\title{
Impact of hand eczema severity on quality of life: a hospital based cross-sectional study
}

\author{
Bharat Bhushan Mahajan', Sandeep Kaur ${ }^{2}$ \\ ${ }^{1}$ Department of Dermatology, Venereology \& Leprology, Government Medical College, Amritsar, Punjab, India, \\ ${ }^{2}$ Department of Dermatology, Venereology \& Leprology, Guru Gobind Singh Medical College \& Hospital, Sadiq Road, \\ Faridkot, Punjab, India
}

Corresponding author: Dr. Sandeep Kaur, E-mail: Docsandeep_2005@yahoo.com

\begin{abstract}
Introduction: Hands are important organs of expression, communication, and are necessary for household and workrelated activity. Thus, hand eczema can deteriorate quality of life. This study aims to find impact of hand eczema severity on quality of life. Methods: A cross-sectional study was done in a tertiary care hospital in Punjab from January to July, 2014. A total of 69 hand eczema patients of either gender aged $\geq 16$ years were enrolled after taking an informed consent. Disease severity was assessed by hand eczema severity index (HECSI) score; and quality of life by dermatology life quality index (DLQI) questionnaire. The data was evaluated using statistical tests like frequency, chi-square, oneway ANOVA, t-test etc. Results: Out of 69 patients, 63.8\% were males and 36.2\% females. The commonest age group affected was $21-40$ years ( $55.1 \%$ cases). Aggravating factors were reported by $76.8 \%$ patients, the commonest trigger being summer season (47.8\%) followed by soaps and detergents (21.7\%). The mean \pm S.D. for DLQI was $6.22 \pm 5.42$ and for HECSI was 18.54 \pm 17.05 . There was no statistically significant impact of age, occupation and duration of disease on DLQI or disease severity except gender (p-value being 0.028 for DLQI; 0.035 for HECSI). There was no significant correlation between HECSI score and DLQI. Conclusion: Majority of the patients with hand eczema had a significant impairment of their quality of life. There was a statistically significant impact of gender on hand eczema severity; although no correlation was found between DLQI and HECSI score in this study.
\end{abstract}

Key words: Hand eczema; Hand eczema severity index; Quality of life

\section{INTRODUCTION}

Hands are important organs of expression, communication, and are necessary for household and work-related activity. Hand eczema is a common and chronic dermatological condition. Though the exact prevalence of hand eczema is difficult to estimate as it is not a reportable disease and many patients even do not seek treatment. An estimated 2-10\% of population is likely to develop hand eczema at some point of time during life. It appears to be the most common occupational skin disease, constituting up to $80 \%$ or more of all occupational contact dermatitides [1]. The disease has onset before 20 years of age in one-third of the patients [2]. Due to its high prevalence, early onset with chronic course and relation to occupation, it can have enormous socioeconomic consequences and a massive impact on patient's quality of life. For the assessment of its impact on quality of life (QoL), generic and dermatology-specific questionnaires can be used as disease-specific questionnaire is missing presently [3]. This study assessed QoL in hand eczema patients presenting in our dermatology outpatient clinic, related QoL to disease severity and morphological subgroup of hand eczema, and identifies various modifying factors influencing QoL.

\section{MATERIALS AND METHODS}

A cross-sectional study was done in the dermatology outpatient department at a tertiary care center in North India from January to July 2014.

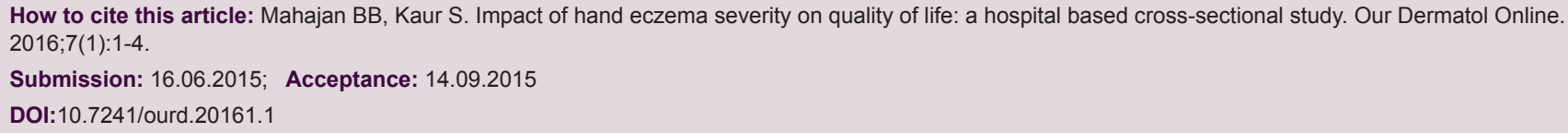




\section{Inclusion Criteria}

All patients of either gender and aged 16 years or more who presented with hand lesions suggestive of eczema were included in the study after informed consent.

\section{Exclusion Criteria}

- Patients less than 16 years of age.

- Patients whose skin scraping for fungus was positive on potassium hydroxide $(\mathrm{KOH})$ mount.

- Patients who had palmar psoriasis (biopsy proved or with other psoriatic skin lesions and/or nail involvement).

- Patients who did not give consent to be part of the study.

Demographic profile, symptoms, details of occupation, duration, and aggravating factors were recorded. Examination included sites of involvement, morphology of the lesions. Morphological diagnosis was categorized as pompholyx, fissured hand eczema, hyperkeratotic hand eczema, nummular hand eczema, fingertip eczema and interdigital eczema.

Data on QoL was obtained from a self-administered questionnaire using the Dermatology Life Quality Index (DLQI). This is a dermatology-specific questionnaire which has been proven useful for assessment of QoL in hand eczema patients [4]. The DLQI is a 10-item questionnaire, which covers six aspects of daily life experienced during the past week: (i) symptoms and feelings, (ii) daily activities, (iii) leisure items, (iv) work and school, (v) personal relationship items, and (vi) treatment. The DLQI score is calculated by summing the score of each question, with a maximum score of 30 and a minimum score of 0 . The higher the score, the greater the impairment of life.

Hongbo, et al. in his study looked at the relationship between DLQI and the patients' views of the overall impairment of their skin-related quality of life. He proposed the following classification of DLQI score: 0 -1: No effect on patient's life, 2-5: Small effect on patient's life; 6-10: Moderate effect on patient's life; 11-20: Very large effect on patient's life; 21-30: Extremely large effect on patient's life. He stated that classifying DLQI will aid in the clinical interpretation of an individual's DLQI score, thus help in making clinical decisions [5]. The severity of hand eczema was assessed using a scoring system (Hand Eczema Severity Index, HECSI) [6]. It includes scoring of morphological signs such as erythema, infiltration, vesicles, fissures, scaling, and oedema as well as scoring of the affected area on the hands (fingertips, fingers, palms, back of hands, and wrists). The final score varies from 0-360.

\section{Statistical Analysis}

The data was evaluated using statistical tests like frequency, chi-square, oneway ANOVA, t-test etc.

\section{RESULTS}

A total of 69 patients were included in the study. Out of these, 63.8\% (44/69) were males and 36.2\% (25/69) were females with M:F ratio being 1.76:1. The commonest age group affected was $21-40$ years ( $55.1 \%$ cases) followed by $41-60$ years $(23.2 \%)$, less than 20 years $(17.4 \%)$ and $>60$ years $(4.3 \%)$. The commonest age of onset of hand eczema was $21-40$ years $(49.3 \%)$ followed by less than 20 years of age (34.8\%). However, males had an earlier onset of disease when compared to females (Table 1).

In our study, $30.4 \%$ were housekeepers followed by construction workers including masons, manual labourers $(30.4 \%)$, farmers $(13.0 \%)$, and others including doctor, engineer, student, driver (21.7\%). About 23.2\% (16/69) patients were illiterate while $34.8 \%(24 / 69)$ had passed primary school and $42.0 \%$ $(29 / 69)$ had read up to secondary school or higher. Around 42\% (29/69) patients had disease for more than 5 years; $36.2 \%$ cases had disease duration between $1-5$ years and only $21.7 \%$ (15/69) had symptoms for less than 1 year. Aggravating factors were reported by $76.8 \%$ patients, the commonest trigger being summer season $(47.8 \%)$ followed by soaps and detergents $(21.7 \%)$, cement $(11.6 \%)$, metals $(10.1 \%)$ and cutting vegetables $(7.2 \%)$. Out of total 5 patients who reported exacerbation of hand eczema with vegetables, all were housewives. Again, $80 \%$ of cases reporting worsening with soaps and detergents were housewives. Based on clinical findings, $44.9 \%$ patients were diagnosed with

\begin{tabular}{|c|c|c|c|c|c|c|}
\hline \multirow{2}{*}{$\begin{array}{l}\text { Age at onset } \\
\text { of disease } \\
\text { (years) }\end{array}$} & \multicolumn{2}{|c|}{ Males } & \multicolumn{2}{|c|}{ Females } & \multicolumn{2}{|c|}{ Total } \\
\hline & $\mathbf{N}$ & $\begin{array}{c}\% \text { of all } \\
\text { males }\end{array}$ & $\mathbf{n}$ & $\begin{array}{l}\% \text { of all } \\
\text { females }\end{array}$ & $\mathbf{n}$ & $\begin{array}{c}\% \text { of all } \\
\text { cases }\end{array}$ \\
\hline$\leq 20$ & 18 & 40.9 & 6 & 24 & 24 & 34.8 \\
\hline $21-40$ & 20 & 45.5 & 14 & 56 & 34 & 49.3 \\
\hline $41-60$ & 5 & 11.4 & 5 & 20 & 10 & 14.5 \\
\hline$>60$ & 1 & 2.3 & 0 & 0 & 1 & 1.4 \\
\hline Total & 44 & 100 & 25 & 100 & 69 & 100 \\
\hline
\end{tabular}


pompholyx, 27.5\% had fissured hand eczema, 23.2\% had hyperkeratotic hand eczema, $2.9 \%$ had nummular eczema, and fingertip eczema was seen in $1.4 \%$ cases (Fig. 1).

The mean \pm S.D. for DLQI was $6.22 \pm 5.42$ and for HECSI was $18.54 \pm 17.05$. The median values for DLQI and HECSI were 4.00 and 12.00 respectively. Dermatology life quality index ranged from 1 to 20 while corresponding range for HECSI was 2 to 84. Statistically significant higher HECSI scores were found in males as compared to females, while no significant difference was found for DLQI values (Table 2).

Age, duration of disease, educational status, and occupation did not significantly affect the quality of life $(P$ values $=0.261,0.386,0.698,0.378)($ Table 3$)$. Disease severity did not show any significant correlation with the above parameters $(P$ values $=0.597,0.782$, $0.645,0.324$ ) (Table 3).

\section{DISCUSSION}

Hand eczema is a common occupational dermatoses requiring dermatological care. Studies published in the past have shown significant negative impact of severity of hand eczema on the quality of life of an individual.

Men were almost twice as commonly affected than females which correlate well with increasing trend of hand eczema seen in males as stated in some of the recent studies $[7,8]$. According to literature, in one-third of patients, the disease occurs before the age of 20 years [9] which is quite similar to what was observed in our study. Also, it was seen in our study that males had earlier onset of disease than females. Higher prevalence and earlier age of onset in males may be attributed to the fact that men are employed in occupations such as construction, farming etc. where they get exposed to numerous allergens which may contribute enormously to hand eczema. Also such exposure starts at a younger age amongst males so cumulative exposure in men is higher than females.

The risk of hand eczema is occupation-related as well, being higher in industrial workers and masons due to exposure to various chemicals [10]. In our study, 34.8\% were housekeepers, $30.4 \%$ were involved in construction work (including masons, construction site labourers)

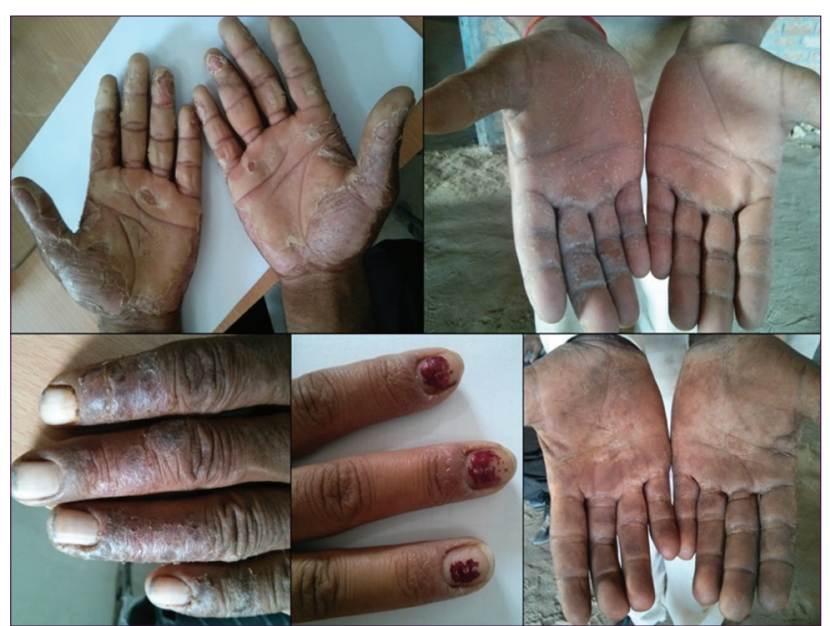

Figure 1: Various morphological patterns of hand eczema seen in our patients.

Table 2: Mean values for DLQI and HECSI for males and females

\begin{tabular}{lcccc}
\hline Scoring system & Total & Males & Females & $p$-value \\
\hline DLQI & 6.22 & 5.32 & 7.80 & 0.067 \\
HECSI & 18.54 & 21.77 & 12.84 & 0.035 \\
\hline
\end{tabular}

Table 3: DLQI and HECSI in terms of gender, age, duration, education status and occupation

\begin{tabular}{lcc}
\hline Variables & \multicolumn{2}{c}{$p$-value } \\
\cline { 2 - 3 } & DLQI & HECSI \\
\hline Gender & 0.067 & 0.035 \\
Age & 0.261 & 0.597 \\
Duration & 0.386 & 0.782 \\
Education & 0.698 & 0.645 \\
Occupation & 0.378 & 0.324 \\
\hline There was no significant correlation between HECSI and DLQI in this study
\end{tabular}

and $13 \%$ were farmers, thereby, predominantly affecting population that is regularly exposed to diverse types of chemical allergens.

The mean DLQI in the study was 6.22, underlining that hand eczema has a significant negative impact on the quality of life. This finding is similar to the observation in other similar studies [11,12].

Similar to the study by Agner et al, it was observed that although females had less severe hand eczema than males, QoL was equally affected [13]. This may stem out of greater cosmetic concern in females when compared to males. However in contrast to their study, age, occupation, and duration of disease did not significantly affect the quality of life or disease severity in our patients. There was no significant correlation between disease severity assessed by HECSI score and quality of life, however patients with even low HECSI score had a significant negative impact on their quality of life. 


\section{CONCLUSION}

Majority of the patients with hand eczema had a significant impairment of their quality of life. There was a statistically significant impact of gender on hand eczema severity; although no correlation was found between DLQI and HECSI score in this study.

\section{Statement of Human and Animal Rights}

All procedures followed were in accordance with the ethical standards of the responsible committee on human experimentation (institutional and national) and with the Helsinki Declaration of 1975, as revised in 2008.

\section{Statement of Informed Consent}

Informed consent was obtained from all patients for being included in the study.

\section{REFERENCES}

1. Elston DM, Ahmed DD, Watsky KL, Schwarzenberger K. Hand dermatitis. J Am Acad Dermatol. 2002;47:291-9.

2. Meding B, Järvholm B. Incidence of hand eczema-a populationbased retrospective study. J Invest Dermatol. 2004;122:873-7.

3. Wallenhammar LM, Nyfjall M, Lindberg M, Meding B. Healthrelated quality of life and hand eczema - a comparison of two instruments, including factor analysis. J Invest Dermatol. 2004;122:1381-89.
4. Cvetkovski RS, Zachariae R, Jensen H, Olsen J, Johansen JD, Agner T. Quality of life and depression in a population of occupational hand eczema patients. Contact Dermatitis. 2006;54:106-111.

5. Hongbo Y, Thomas CL, Harrison MA, Salek MS, Finlay AY. Translating the science of quality of life into practice: What do dermatology life quality index scores mean? J Invest Dermatol. 2005;125:659-64.

6. Held E, Skoet R, Johansen JD, Agner T. The hand eczema severity index (HECSI): A scoring system for clinical assessment of hand eczema. A study of inter- and intra-observer reliability. $\mathrm{Br}$ Dermatol. 2005;152:302-7.

7. Handa S, Kaur I, Gupta T, Jindal R. Hand eczema: Correlation of morphologic patterns, atopy, contact sensitization and disease severity. Indian J Dermatol Venereol Leprol. 2012;78:153-8.

8. Suman M, Reddy BS. Pattern of contact sensitivity in Indian patients with hand eczema. J Dermatol. 2003;30:649-54.

9. Meding B, Järvholm B. Incidence of hand eczema-a populationbased retrospective study. J Invest Dermatol. 2004;122:873-7.

10. Elston DM, Ahmed DD, Watsky KL, Schwarzenberger K. Hand dermatitis. J Am Acad Dermatol. 2002;47:291-9.

11. Moberg C, Alderling M, Meding B. Hand eczema and quality of life: A population-based study. Br J Dermatol. 2009;161:397-403.

12. Thomson KF, Wilkinson SM, Sommer S, Pollock B. Eczema: Quality of life by body site and the effect of patch testing. Br J Dermatol. 2002;146:627-30.

13. Agner T, Andersen KE, Brandao FM, Bruynzeel DP, Bruze M, Frosch P, et al. Hand eczema severity and quality of life: A crosssectional, multicentre study of hand eczema patients. Contact Dermatitis. 2008;59:43-7.

Copyright by Bharat Bhushan Mahajan, et al. This is an open access article distributed under the terms of the Creative Commons Attribution License, which permits unrestricted use, distribution, and reproduction in any medium, provided the original author and source are credited.

Source of Support: Nil, Conflict of Interest: None declared. 